\title{
Free Amino Acids in Human Amniotic Fluid. A Quantitative Study by Ion-Exchange Chromatography
}

\author{
Harvey L. Levy ${ }^{[38]}$ and Paul P. Montag \\ Department of Neurology, Harvard Medical School; the Joseph P. Kennedy Jr. Memorial \\ Laboratories, Massachusetts General Hospital, Boston, Massachusetts; and the Worcester \\ Hahnemann Hospital, Worcester, Massachusetts, USA
}

\begin{abstract}
Extract
Amniotic fluid was collected at inductive amniotomy or just prior to delivery following full-term uncomplicated pregnancies. Table I lists the means, ranges, and standard deviations for the concentrations of amino acids obtained by ion-exchange chromatography of 16 specimens of amniotic fluid. Each specimen contained the following 22 amino acids: taurine, aspartic acid, threonine, serine, glutamine, proline, glutamic acid, citrulline, glycine, alanine, $\alpha$-aminobutyric acid, valine, cystine, methionine, isoleucine, tyrosine, phenylalanine, ornithine, lysine, histidine, and arginine. In addition, tryptophan, which could not be detected by the ion-exchange chromatographic method employed, was found in each specimen by paper chromatography. The amino acids present in amniotic fluid were the same as those found in samples of maternal vein, umbilical artery, and umbilical vein serum (table II). Comparisons were made in the concentrations of several amino acids among amniotic fluid, maternal serum, umbilical artery and vein serum, and perinatal urine (table II). Taurine was present in considerably greater concentration in amniotic fluid than in maternal serum. This amino acid is also present in large quantities in umbilical artery and vein serum (table II) and is by far the greatest single contributor to the total free amino acid pool in perinatal urine [1]. In contrast, amino acids such as leucine, valine, and threonine, which are present in much smaller amounts in amniotic fluid than in either maternal or umbilical serum, are found in even lower concentrations in perinatal urine [1]. These comparisons suggest that amniotic fluid is derived from at least three sources, maternal blood, fetal blood, and fetal urine, a finding compatible with existing evidence $[3,24,27,30]$.

In order to detect metabolic disease at an early stage of pregnancy, it might be advantageous to obtain amniotic fluid early in pregnancy. Preliminary studies in this laboratory have revealed no significant differences in the concentration of free amino acid in amniotic fluid obtained between the sixth and ninth months of gestation.
\end{abstract}

\section{Speculation}

The quantitative study of free amino acids in amniotic fluid could enable certain metabolic disorders or transport defects to be identified in utero, aid in the counseling of parents, and assist in establishing therapy prior to birth. 


\section{Introduction}

Levels of free amino acids in human amniotic fluid have received little study. Only eight studies of this type $[2,6,21-23,26,29,31]$ have appeared. All of these employed paper chromatography for detection and therefore were essentially qualitative or semiquantitative. In only three studies was quantitation of amino acids attempted. Two studies involved visual comparison with standards by paper chromatography [21,31], and in a third, amino acids eluted from the paper chromatogram were measured by spectrophotometry [26]. Two additional studies reported levels of a single amino acid using a specific quantitative analysis [11, 17].

In the present study, we measured the free amino acid content of amniotic fluid using automated ionexchange column chromatography. This quantitative approach may prove to be of value in the diagnosis of inherited disorders involving amino acids.

\section{Materials and Methods}

\section{Subjects}

Amniotic fluid was collected during an inductive amniotomy or just prior to delivery following full-term uncomplicated pregnancies. Only those pregnancies having a calculated duration of 39 to 41 weeks and terminating in the delivery of single, normal infant weighing between $2700-3400 \mathrm{~g}$ were included. When labor preceded the collection of amniotic fluid, the duration varied from 1 to 9 hours. The periods of fasting prior to the collection of the amniotic fluid ranged from 5 to 22 hours. In most instances, inductive amniotomy was performed and the mother received no medication prior to collection. When labor preceded collection, meperidine [33], scopolamine, and secobarbital [34] were administered 1 to 9 hours prior to delivery; on six occasions, $5 \%$ glucose in water with added pitocin was administered by intravenous injection. All specimens analyzed were grossly free of blood and meconium and had a $\mathrm{pH}$ of 7.0 or greater. At postpartum evaluation, each of the mothers was normal. The babies were followed for periods of 5 to 18 months and all had remained clinically normal.

\section{Collection of Amniotic Fluid}

For each collection, a sterile cup was held just within the vaginal orifice at the time of artificial rupture of the fetal membranes. The fluid gushed or flowed freely into the cup. Five to $20 \mathrm{ml}$ of fluid was transferred to a sterile test tube and immediately refrigerated at $4^{\circ}$; one to two hours later, all specimens were placed at $-20^{\circ}$. Within five days after collection, each speci- men was thawed and filtered through Whatman No. 1 filter paper. Two $\mathrm{ml}$ of each specimen was then deproteinized with approximately $25 \mathrm{mg}$ of solid sulfosalicylic acid and centrifuged at $2000 \mathrm{rpm}$ for $20 \mathrm{~min}-$ utes. A portion of the supernatant was used for ionexchange chromatography.

\section{Collection of Blood}

Several minutes prior to delivery, maternal blood was collected by venipuncture. Umbilical artery and vein bloods from the newborn were aspirated from the respective vessels within the umbilical cord several minutes after delivery of the placenta. Serum from each of the clotted samples was separated from the clot by centrifugation within one hour following collection and was immediately frozen at $-20^{\circ}$. Within five to seven days after collection, each serum was thawed, deproteinized with approximately $25 \mathrm{mg}$ of solid sulfosalicylic acid, and centrifuged at $2000 \mathrm{rpm}$ for 20 minutes. A portion of the supernatant was used for ion-exchange chromatography.

\section{Ion-Exchange Chromatography}

For automated ion-exchange chromatography, 250 $\mu \mathrm{l}$ of amniotic fluid or serum supernatant was pipetted into a $50 \mathrm{~cm}$ column of resin [35]. A Technicon amino acid analyzer was used for the analysis according to the method of Efron [8]. One-tenth $\mu$ mole of cysteic acid was used as the reference standard. A second analysis was performed using $1 \mathrm{ml}$ of the supernatant in order to detect amino acids present at low concentrations.

\section{Paper Chromatography}

To supplement column chromatography, $100 \mu \mathrm{l}$ of filtered but otherwise untreated amniotic fluid was studied by paper chromatography to determine amino acids [9]. For the first dimension, amniotic fluid was applied to a strip of Whatman No. 3 chromatography paper and subjected to electrophoresis at 3500 volts and 200 ma for 40 minutes in a buffer of $8 \%$ formic acid, pH 1.6. The strip was then dried and sewn to a large rectangle of Whatman No. 3 chromatography paper, which was chromatographed in butanol-acetic acid-water (12:3:5) for 10-12 hours (or overnight). Following chromatography, the paper was dried and stained with $0.2 \%$ ninhydrin in ethanol. The colors were developed at room temperature for two hours, followed by heating at $100^{\circ}$ for 3 minutes.

Imino acids (proline and hydroxyproline) were detected by applying $250 \mu \mathrm{l}$ of the filtered amniotic fluid to a sheet of Whatman No. 3 chromatography paper and chromatographing in butanol-acetic acid-water (12:3:5) for 8 hours. After drying, the paper was stained with $0.2 \%$ isatin in acetetone and heated to 
$100^{\circ}$ for 10 minutes. Proline was identified by a characteristic blue color and $\mathrm{Rf}$ value. The paper was then over-stained with Ehrlich's reagent to detect hydroxyproline, which gave a pink color in this system.

Indole compounds were detected by unidimensional paper chromatography in butanol-acetic acid-water and by the bidimensional paper chromatographic method of Jepson [16]. These chromatograms were stained with Ehrlich's reagent.

\section{Results}

Figure 1 depicts a typical chromatogram of a complete automated ion-exchange analysis. Table $\mathrm{I}$ lists the means, ranges, and standard deviations for the con- centrations of 22 amino acids obtained by ion-exchange chromatography of sixteen specimens. In addition to these amino acids, tryptophan, which cannot be detected by the ion-exchange chromatographic method employed, was found in every sample when examined by paper chromatography. When citrulline, $\alpha$-aminobutyric acid, methionine, isoleucine, and arginine were occasionally found to be present in amounts of $<0.005$ $\mu \mathrm{moles} / \mathrm{ml}$, the lowest limit of accurate computation, these compounds are listed as being present in 'trace' quantities. Commonly, the aspartic acid peak was slurred and could not be calculated. In six analyses, threonine, serine, and glutamine did not resolve well enough to permit accurate calculation. Quantitative figures are given only for the compound that did show a clear separation. Although proline was seen in every
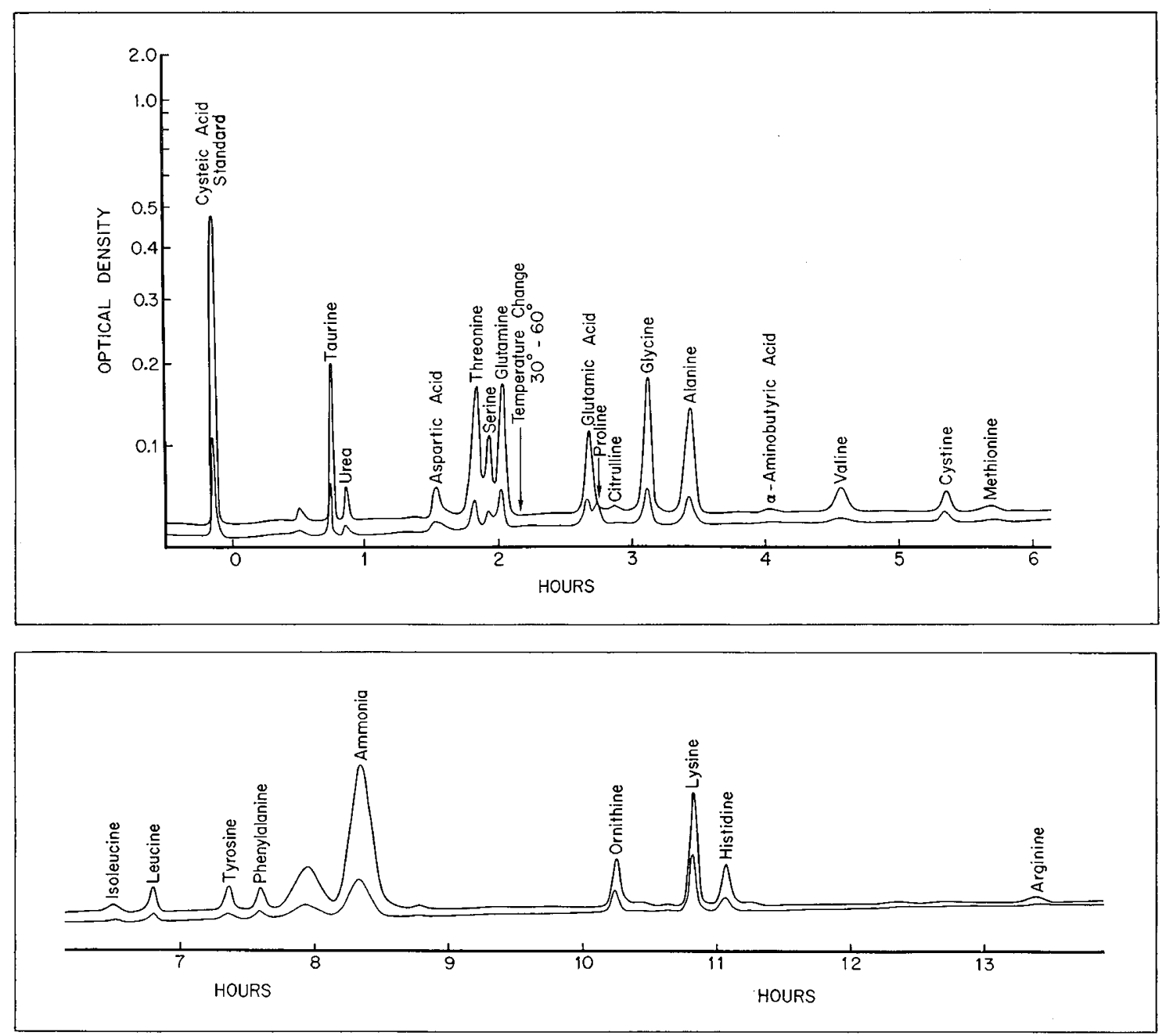

Fig. 1. Chromatographic analysis of the amino acids in $250 \mathrm{ml}$ of normal human amniotic fluid. The top line indicates the tracing read spectrophotometrically at $570 \mathrm{~m} \mu$; the bottom line indicates the tracing at $440 \mathrm{~m} \mu$. 


\begin{tabular}{|c|c|c|c|c|c|c|c|c|c|c|c|c|c|c|c|c|c|c|c|}
\hline & 1 & 2 & 3 & 4 & 5 & 6 & 7 & 8 & 9 & 10 & 11 & 12 & 13 & 14 & 15 & 16 & $\begin{array}{c}\text { Aver- } \\
\text { age }\end{array}$ & Range & Std. dev. \\
\hline Taurine & .083 & .158 & .077 & .077 & .132 & .160 & .167 & .225 & .150 & .080 & .058 & .108 & .117 & .100 & .057 & .060 & .113 & $.057-.225$ & \pm .049 \\
\hline Aspartic acid & .022 & $\mathrm{NG}$ & $\mathrm{NC}$ & $\mathrm{NG}$ & $\mathrm{NG}$ & $\mathrm{NG}$ & $\mathrm{NC}$ & $\mathrm{NG}$ & $\mathrm{NC}$ & $\mathrm{NC}$ & $\mathrm{NG}$ & .044 & $\mathrm{NG}$ & $\mathrm{NC}$ & .013 & $\mathrm{NG}$ & .026 & $.013-.044$ & $\mathrm{NG}$ \\
\hline Threonine & .150 & .192 & .106 & .086 & $\mathrm{NC}$ & .079 & .180 & .194 & .143 & .107 & .114 & .190 & .174 & .148 & .139 & .082 & .139 & $.079-.194$ & \pm .041 \\
\hline Serine & .083 & .113 & .134 & .081 & .166 & .163 & $\mathrm{NG}$ & .150 & .106 & $\mathrm{NC}$ & .118 & .119 & .072 & $\mathrm{NG}$ & $\mathrm{NG}$ & $\mathrm{NC}$ & .119 & $.072-.166$ & \pm .033 \\
\hline Glutamine & .220 & .271 & .379 & $\mathrm{NG}$ & .208 & .244 & $\mathrm{NC}$ & .281 & .173 & .174 & .191 & .203 & .138 & .250 & .233 & .153 & .223 & $.138-.379$ & \pm .062 \\
\hline Proline & .126 & .124 & $\mathrm{SG}$ & $\mathrm{SC}$ & .093 & $\mathrm{SG}$ & .080 & $\mathrm{SG}$ & .116 & $\mathrm{SC}$ & .085 & .094 & .101 & $\mathrm{SG}$ & $\mathrm{SG}$ & .112 & .103 & $.080-.126$ & \pm .017 \\
\hline Glutamic acid & .050 & .129 & .048 & .122 & .128 & .152 & .069 & .080 & .152 & .077 & .040 & .120 & .327 & .111 & .056 & .057 & .107 & $.040-.327$ & \pm .126 \\
\hline Gitrulline & .008 & .010 & .007 & tr. & .020 & tr. & tr. & tr. & .013 & tr. & tr. & .007 & .020 & .010 & .011 & .007 & .011 & tr. -.020 & \pm .005 \\
\hline Glycine & .144 & .272 & .176 & .113 & .181 & .214 & .122 & .173 & .188 & .125 & .164 & .192 & .418 & .204 & .155 & .117 & .185 & $.117-.418$ & \pm .075 \\
\hline Alanine & .220 & .198 & .205 & .180 & .188 & .213 & .182 & .229 & .175 & .151 & .190 & .172 & .372 & .178 & .136 & .108 & .194 & $.108-.372$ & \pm .057 \\
\hline$\alpha$-Aminobutyric acid & .005 & .012 & tr. & tr. & .011 & tr. & tr. & .008 & .009 & tr. & tr. & tr. & .019 & tr. & tr. & tr. & .011 & tr. -.019 & \pm .004 \\
\hline Valine & .088 & .108 & .063 & .056 & .067 & .068 & .065 & .078 & .069 & .053 & .075 & .064 & .059 & .082 & .047 & .031 & .067 & $.031-.108$ & \pm .018 \\
\hline Cystine & .060 & .059 & .065 & .031 & .083 & .071 & .048 & .080 & .075 & .123 & .073 & .078 & .084 & .075 & .068 & .064 & .071 & $.031-.123$ & \pm .019 \\
\hline Methionine & .010 & .019 & 0.11 & .009 & .011 & .013 & tr. & tr. & .010 & tr. & tr. & .012 & .018 & .009 & tr. & .007 & .012 & tr. -.019 & \pm .006 \\
\hline Isoleucine & .016 & .025 & .015 & .031 & .012 & .018 & .020 & .018 & .026 & tr. & .028 & .014 & tr. & .036 & .008 & .012 & .020 & tr. -.036 & \pm .008 \\
\hline Leucine & .030 & .082 & .031 & .037 & .035 & .041 & .059 & .042 & .052 & .024 & .044 & .039 & .029 & .082 & .027 & .027 & .043 & $.024-.082$ & \pm .026 \\
\hline Tyrosine & .031 & .045 & .027 & .036 & .027 & .029 & .043 & .033 & .028 & .022 & .037 & .036 & .059 & .044 & .024 & .036 & .035 & $.022-.059$ & \pm .010 \\
\hline Phenylalanine & .046 & .056 & .034 & .033 & .032 & .032 & .039 & .036 & .037 & .049 & .037 & 0.41 & .039 & .049 & .029 & .017 & .038 & $.017-.056$ & \pm .010 \\
\hline Ornithine & .026 & .045 & .032 & .034 & .030 & .042 & .079 & .047 & .052 & .046 & .022 & .072 & .048 & .067 & .039 & .034 & .045 & $.022-.079$ & \pm .016 \\
\hline Lysine & .113 & .174 & .114 & .088 & .200 & .126 & .133 & .159 & .130 & .253 & .112 & .164 & .211 & .146 & .143 & .094 & .148 & $.088-.253$ & \pm .045 \\
\hline Histidine & .044 & .052 & .043 & .020 & .047 & .046 & .056 & .031 & .026 & .033 & .055 & .067 & .080 & .065 & .032 & .033 & .046 & $.020-.080$ & \pm .016 \\
\hline Arginine & .046 & .034 & .028 & tr. & .023 & tr. & .029 & tr. & tr. & .018 & .037 & .011 & .020 & .039 & .016 & tr. & .028 & tr. -.056 & \pm .013 \\
\hline
\end{tabular}

$\mathrm{NC}=$ not calculable.

$\mathrm{SC}=$ single channel (not read at wave length $440 \mathrm{~m} \mu$ ).

tr. = trace (too small to calculate). 

and perinatal urine

\begin{tabular}{|c|c|c|c|c|c|}
\hline $\begin{array}{l}\text { Amino acid } \\
(\mu \mathrm{moles} / \mathrm{ml})\end{array}$ & Amniotic fluid $(16) *$ & Maternal serum (10) & $\begin{array}{l}\text { Umbilical artery } \\
\text { serum }(10)\end{array}$ & $\begin{array}{l}\text { Umbilical vein serum } \\
\qquad(10)\end{array}$ & $\begin{array}{c}\text { Perinatal urine } \\
\text { (calculated from } \\
\text { Armstrong et al. [1]) }\end{array}$ \\
\hline Taurine & $0.113(0.057-0.225) * *$ & $0.045(0.029-0.094)$ & $0.126(0.121-0.135)$ & $0.145(0.110-0.204)$ & $1.36 \quad(0.575-1.76)$ \\
\hline Threonine & $0.139(0.079-0.194)$ & $0.209(0.181-0.402)$ & $0.310(0.294-0.325)$ & $0.301(0.280-0.324)$ & $0.084(0.042-0.396)$ \\
\hline Serine & $0.119(0.072-0.166)$ & $0.227(0.129-0.297)$ & $0.211(0.195-0.227)$ & $0.234(0.209-0.277)$ & $0.176(0.114-1.19)$ \\
\hline Glutamine & $0.223(0.138-0.379)$ & $0.360(0.347-0.378)$ & $0.280(0.210-0.350)$ & $0.369(0.347-0.385)$ & $\begin{array}{l}0.176(\text { Glu-N and } \\
\text { Asp-N) }(0.013-0.900)\end{array}$ \\
\hline Proline & $0.103(0.080-0.126)$ & $0.096(0.084-0.103)$ & $0.164(0.135-0.211)$ & $0.210(0.193-0.234)$ & $0.032(0.014-0.180)$ \\
\hline Glutamic acid & $0.107(0.040-0.327)$ & $0.115(0.055-0.172)$ & $0.233(0.152-0.321)$ & $0.271(0.107-0.347)$ & $0.020(0.003-0.108)$ \\
\hline Citrulline & $0.011(\operatorname{tr} .-0.020)$ & $0.012(0.005-0.027)$ & $0.015(0.009-0.021)$ & $0.013(0.005-0.021)$ & - \\
\hline Glycine & $0.185(0.117-0.418)$ & $0.177(0.128-0.281)$ & $0.285(0.254-0.317)$ & $0.280(0.222-0.364)$ & $0.512(0.224-2.70)$ \\
\hline Alanine & $0.194(0.108-0.372)$ & $0.243(0.184-0.437)$ & $0.340(0.282-0.376)$ & $0.338(0.282-0.410)$ & $0.128(0.028-0.468)$ \\
\hline$\alpha$-Aminobutyric acid & $0.011($ tr. -0.019$)$ & $0.014(0.009-0.016)$ & $0.014(0.008-0.015)$ & $0.027(0.017-0.047)$ & - \\
\hline Valine & $0.067(0.031-0.108)$ & $0.122(0.106-0.250)$ & $0.184(0.131-0.219)$ & $0.196(0.147-0.254)$ & $0.16(0.007-0.504)$ \\
\hline Cystine & $0.071(0.031-0.123)$ & $\mathrm{NA} * * *$ & NA & NA & NA \\
\hline Methionine & $0.012(\quad$ tr. -0.019$)$ & $0.016(0.014-0.030)$ & $0.035(0.026-0.052)$ & $0.028(0.019-0.033)$ & tr. -0.025 \\
\hline Isoleucine & $0.020(\quad \operatorname{tr} .-0.036)$ & $0.041(0.031-0.086)$ & $0.061(0.042-0.086)$ & $0.057(0.043-0.075)$ & $0.092(0.044-0.336)$ \\
\hline Leucine & $0.043(0.024-0.082)$ & $0.097(0.073-0.173)$ & $0.112(0.076-0.154)$ & $0.123(0.088-0.160)$ & $0.012(0.010-0.140)$ \\
\hline Tyrosine & $0.035(0.022-0.059)$ & $0.030(0.025-0.077)$ & $0.054(0.046-0.061)$ & $0.057(0.036-0.075)$ & $0.016(0.003-0.072)$ \\
\hline Phenylalanine & $0.038(0.017-0.056)$ & $0.068(0.053-0.100)$ & $0.084(0.071-0.090)$ & $0.086(0.061-0.129)$ & $0.016(0.003-0.108)$ \\
\hline Ornithine & $0.045(0.022-0.079)$ & $0.053(0.038-0.062)$ & $0.166(0.146-0.199)$ & $0.170(0.091-0.281)$ & $0.008(0.003-0.036)$ \\
\hline Lysine & $0.148(0.088-0.253)$ & $0.128(0.111-0.248)$ & $0.353(0.293-0.400)$ & $0.358(0.292-0.457)$ & $0.112(0.044-0.468)$ \\
\hline Histidine & $0.046(0.020-0.080)$ & $0.080(0.057-0.161)$ & $0.125(0.109-0.138)$ & $0.125(0.112-0.146)$ & $0.072(0.027-0.396)$ \\
\hline Arginine & $0.028(\operatorname{tr} .-0.056)$ & $0.072(0.026-0.166)$ & $0.107(0.059-0.111\rangle$ & $0.106(0.072-0.131)$ & $0.016(0.005-0.112)$ \\
\hline
\end{tabular}

* Numbers in parentheses indicate number of samples.

** Ranges are given in parentheses.

*** Not accurate. 
specimen examined by paper chromatography, it was not recorded quantitatively in seven specimens because analyses of these samples did not include spectrophotometric recordings at a wave length of $440 \mathrm{~m} \mu$. The analysis in which $1 \mathrm{ml}$ of amniotic fluid was applied to the column did not reveal a greater number of amino acids than was noted in the standard analyses.

Glutamine is not separable from asparagine in the ion-exchange scheme used but no asparagine was noted by paper chromatography even when five times the usual amount of amniotic fluid was applied to the paper. It was concluded that either no asparagine was present in amniotic fluid or that the amount present was too small to detect.

The analyses resembled qualitatively those obtained with human serum. The concentrations of most of the individual amino acids in amniotic fluid were approximately $50-75 \%$ of those of the corresponding concentrations present in maternal serum. Taurine was present in amniotic fluid in over twice the concentration observed in maternal serum (table II). This amino acid has been found in very large quantities in urine collected during the perinatal period from normal mature newborns [1].

The concentration of cystine was far greater in amniotic fluid than in maternal serum. Amniotic fluid, however, contains much less protein than does serum [4], and since cystine combines with protein [5], it is likely that the low level of free cystine in serum was a result of this artifact. The values for free cystine obtained by Ghadim and Pecora [13] in maternal plasma deproteinized shortly after venipuncture are very similar to the present values reported for amniotic fluid. The maternal serum used in the present study was not deproteinized for several days following venipuncture.

ARMSTRONG et al. [1] reported that ethanolamine is present in large amounts in perinatal urine. We did not detect this amino acid in amniotic fluid either by ion-exchange or paper chromatography. Neither did we detect other amino acids such as phosphoethanolamine, homocitrulline, $\beta$-aminoisobutyric acid, hydroxylysine, 1-methylhistidine, and 3-methylhistidine, all of which are present in perinatal urine. Since concentrations of these latter amino acids in urine are low, the resulting concentrations in amniotic fluid might be too small for detection by standard methods.

Neither hydroxyproline nor cystathionine could be detected by ion-exchange or paper chromatography. The absence of hydroxyproline in these analyses was unexpected, since KIviRIKKo et al. [17] found concentrations as high as $0.20 \mu$ moles $/ \mathrm{ml}$ in amniotic fluid. Similarly, our method may have been insufficiently sensitive to detect cystathionine in the concentrations reported by FRIMPTER et al. [11].
Neither the time of amniotic fluid collection (whether after inductive amniotomy prior to labor or at the time of delivery following labor), the method of collection of amniotic fluid, the duration of maternal fasting, nor the presence of medication had any demonstrable effect on the quality or quantity of amino acids in amniotic fluid.

\section{Discussion}

In order to utilize amniotic fluid for the investigation of amino acid disorders, accurate information concerning the quality and quantity of free amino acids should be available. The present study presents this information from 16 normal pregnancies. Use of automated ion-exchange column chromatography and paper chromatography permitted detection of 23 free amino acids. PALLrEZ et al. [22] reported a total of 19 free amino acids in human amniotic fluid. Of these 19, we were able to detect all but $\beta$-alanine and hydroxyproline; in addition, we found glutamine, citrulline, isoleucine, phenylalanine, ornithine, and tryptophan. Quantitatively, we detected glutamine in the greatest concentration, followed by alanine and glycine. In semiquantitative investigations, WIRTSCHAFTER [31] reported that aspartic acid, lysine, and glutamine were the amino acids present in highest amount in human amniotic fluid [31]. ORLANDi [21] found glycine and alanine in greatest concentrations, and SAssi [26] concluded that cystine was present in the greatest amount.

Several amino acids revealed wide ranges of concentrations among various samples. Most notable among these was glutamic acid. Specimen No.13 contained the greatest concentration of glutamic acid and the least concentration of glutamine; conversely, specimen No. 3 contained the greatest concentration of glutamine and second lowest concentration of glutamic acid (table I). Since the conversion of glutamic acid to glutamine can be mediated by human cells [7], as well as by animal tissues $[14,25,28]$ and bacteria [12], the ratio of glutamic acid: glutamine in amniotic fluid could conceivably be altered by placental metabolism or by bacterial contamination of amniotic fluid. Fluids that have been frozen for several weeks exhibit high concentrations of glutamic acid and low concentrations of glutamine [10], but this source of error appears unlikely in the present study since the period of storage was brief. The variations in the concentrations of other amino acids among samples were similar to the variations found in maternal serum, umbilical artery and vein serum, and in perinatal urine [1].

The amino acids present in amniotic fluid are the same as those found in maternal blood and in umbilical artery and vein serum (table II). Perinatal urine con- 
tains all but two (citrulline and $\alpha$-aminobutyric acid) of the free amino acids present in amniotic fluid, in addition to ten amino acids not identified [1]. Comparisons may be made in the concentrations of several amino acids in amniotic fluid, maternal serum, umbilical artery and vein serum, and perinatal urine (table II). Taurine is present in considerably greater quantity in amniotic fluid than in maternal serum. This amino acid is also present in large quantities in umbilical artery and vein serum and is by far the greatest single contributor to the total free amino acid pool in perinatal urine [1]. In contrast, amino acids such as leucine, valine, and threonine, which are present in much smaller amounts in amniotic fluid than in either maternal or umbilical serum, are found in even lower concentrations in perinatal urine. These quantitative comparisons suggest that amniotic fluid is derived from at least three sources (maternal blood, fetal blood, and fetal urine) $[3,24,27,30]$. Other possible sources of amino acids in amniotic fluid include the amniotic membrane, vernix caseosa [19], and fetal skin.

The possible value of the study of amniotic fluid in the diagnosis of amino acid metabolism has received little attention. Recent findings, however, suggest that this is an important and potentially valuable fluid for such investigations. JEFFCOATE et al. [15] were able to diagnose a case of the adrenogenital syndrome prior to birth by detecting elevated levels of the 17-ketosteroids and of pregnanetriol in amniotic fluid. Woolf et al. [32] have found that the amniotic fluid of a mother who had atypical phenylketonuria with hyperphenylalaninemia, and whose baby was normal, contained a high concentration of phenylalanine.

Specimens used in this study were obtained following pregnancies with full-term gestation periods. In the prenatal detection of metabolic disease, however, it would be advantageous to obtain specimens early in pregnancy. This could be safely accomplished by the technique of transabdominal aminocentesis [20]. Preliminary data from this laboratory [18] reveal no significant differences in the levels of free amino acid in amniotic fluid obtained between the sixth and ninth months of gestation.

\section{Summary}

Quantitative analysis by automated ion-exchange column chromatography reveals that the free amino acids in human full-term amniotic fluid are identical to those present in maternal and umbilical cord serum. In addition, many of the free amino acids that have been reported in neonatal urine are also present in amniotic fluid. The concentrations of the free amino acids in amniotic fluid are $50-75 \%$ of the respective concentrations in maternal serum.

In this study, 23 free amino acids were detected in amniotic fluid. Glutamine was present in the highest concentration, followed by alanine and glycine. Citrulline and $\alpha$-aminobutyric acid were present in the lowest concentrations.

These data may establish a base for studies concerned with the use of amniotic fluid as a tool for prenatal diagnosis of amino acid metabolic and transport disorders.

\section{References and Notes}

1. Armstrong, M.D.; Yates, K.N. and Connelly, J.P.: Amino acid excretion of newborn infants during the first twenty-four hours of life. Pediatrics 33: 975 (1964).

2. Bevis, D.C.A.: Composition of liquor amnii in haemolytic disease of newborn. Lancet ii: 443 (1950).

3. Bevis, D. C. A.: Blood pigments in haemolytic disease of the newborn. J. Obstet. Gynaec. Brit. Emp. 63: 68 (1956).

4. Bonsnes, R.W.: Composition of amniotic fluid. Clin. obstet. gynec. 9: 440 (1966).

5. Garson, N.A.J.; Cusworth, D.C.; Dent, C.E.; Fiezd, C. M. B.; Neill, D.W. and Westall, R. G.: Homocystinuria: A new inborn error of metabolism associated with mental deficiency. Arch. Dis. Childh. 38: 425 (1963).

6. DeMarco, G.: Aminoacidie chetoacidi presenti nel liquido amniotico. G. Biochim. 3: 296 (1954).

7. DeMARS, R.: The inhibition by glutamine of glutamyl transferase formation in cultures of human cells. Biochim. biophys. Acta 27: 435 (1958).

8. EFRON, M.L.: Quantitative estimation of amino acids in physiological fluids using a Technicon amino acid analyzer; in Automation in analytical chemistry (ed. SkegGs, L.T.), pp.637-642 (Mediad, New York 1966).

9. EFRON, M. L.: High voltage paper electrophoresis; in Chromatographic and electrophoretic techniques (ed. Smrru, I.), vol. II, 2nd ed. (in press).

10. Efron, M.L.; Shin, V.E. and Levy, H.L.: Unpublished data.

11. Frimpter, G.W.; Greenberg, A.J.; Hilgarten, M. and Fuchs, F.: Cystathioninuria : management. Amer.J. Dis. Child. 113: 115 (1967).

12. FRY, B.A.: Glutamine synthesis by micrococcus pyogenes var. aureus. Biochem.J. 59: 579 (1966).

13. Ghadimi, $H$. and Pecora, P.: Free amino acids of cord plasma as compared with maternal plasma during pregnancy. Pediatrics 33: 500 (1964). 
14. Gothoskar, B.P.; Raina, P.N. and RamakrishNAN, G.Y.: Glutamine synthetase in adult-henheart tissue. Biochim. biophys. Acta 37: 477 (1960).

15. Jeffioate, T.N.A.; Fliegner, J.R.H.; Russell, S.H.; Davis, J.C. and WAdE, A.P.: Diagnosis of the adrenogenital syndrome before birth. Lancet ii: 553 (1965).

16. Jepson, J.B.: Paper chromatography of urinary indoles. Lancet ii: 1009 (1955).

17. Krvirikko, K. I.; Kolvusalo, M. and Koivusalo, P.: Free and bound hydroxyproline in the human amniotic fluid in early and full-term pregnancy. Ann.clin.gynaec. fenn. 52: 356 (1963).

18. Levy, H. L. : Unpublished data.

19. Levy, H. L. and Montag, P. P. : Unpublished data.

20. Liley, A.W. : Liquor amnii analysis in the management of the pregnancy complicated by rhesus sensitization. Amer.J. Obstet. Gynec. 82: 1359 (1961).

21. Orlandi, G.; Torsello, R.V. e Bottiglioni, F.: Analisi qualitativa e dosaggio semiquantitativo degli aminoacidi contenuti nel liquido amniotico. Attual. Ostet. Ginec. 4: 871 (1958).

22. Palliez, R.; Biserte, G.; Cotteel, P. et Delecom, M.: Biochimie du liquide amniotique: les protides. Bull. Fédér. Gynéc. Obstét. franç. 6: 162 (1954).

23. Paton, J. B. and Wallby, M. L. : Analysis of amino acid present in biological material by chromatographic methods available for routine clinical use. Med.J.Austr. 2: 639 (1953).

24. Potter, E.L.: Pathology of the fetus and the infant, 2nd ed., p. 48 (Year Book, Chicago 1961).

25. Reiner, J.M. and Hudson, P.B.: Effect of age upon glutamine synthesis and glutamine amide exchange of rat liver, kidney, and testis. J. Urol. 70: 627 (1953).
26. SAssi, D.: Sulla presenza degli aminoacidi nel liquido amniotico. Monogr. Ostet. Ginec. 33: 683 (1962).

27. Seppala, M.; Ruoszahtr, E. and TallberG, Th.: Genetical evidence for maternal origin of amniotic fluid proteins. Ann. Med.exp. Fenn. 44: 6 (1966).

28. Speak, J.F.: The synthesis of glutamine in pigeon liver dispersions. J. biol. Ghem. 179: 1387 (1949).

29. Thomas, J. A. and Thiery, J. P.: The use of deproteinized and purified amniotic fluid. Culture and prolonged conservation of the tissues; microbiological cultures. Bull. Soc. Chim. biol. 35: 841 (1953).

30. Usategui-Gomez, M. and,Morgan, D. F.: Maternal origin of the group specific (Gc) proteins in amniotic fluid. Nature, Lond. 212: 1600 (1966).

31. Wirtschafter, Z.L. : Free amino acids in human amniotic fluid, fetal and maternal serum. Amer.J. Obstet. Gynec. 76: 1219 (1958).

32. Woolf, L. I. ; Ounsted, C.; Lee, D.; Humphrey, M.; Cheshire, N.M. and Steed, G.R.: Atypical phenylketonuria in sisters with normal offspring. Lancet $i i$ : 464 (1961).

33. Demerol (Winthrop Laboratories).

34. Seconal (Eli Lilly and Co.).

35. Spherix xx-8-60-0.

36. The authors wish to acknowledge the technical assistance provided by Miss MARyellen McGarTHY.

37. This investigation was supported by $\mathrm{NIH}$ grants 1 F2 HO-32137-02 and NB-05096 from the U.S. Public Health Service and by a grant from the Kennedy Foundation.

38. Request for reprints should be addressed to: HARvey L. Levy, M.D., Massachusetts General Hospital, Neurology Research, Boston, Mass. 02114 (USA). 